\title{
A Study on Factors Influencing Investment Decision of Pondicherrians
}

\author{
G. Madan Mohan*, Keerthana \\ Department of Management Studies, School of Management, Pondicherry University, Puducherry-605014, India.
}

\author{
How to cite this paper: G. Madan Mohan, \\ Keerthana. (2021) A Study on Factors \\ Influencing Investment Decision of Pondi- \\ cherrians. Journal of Humanities, Arts and \\ Social Science, 5(2), 255-262. \\ DOI: 10.26855/jhass.2021.07.009 \\ Received: August 18, 2021 \\ Accepted: September 12, 2021 \\ Published: October 9, 2021 \\ *Corresponding author: G. Madan \\ Mohan, Department of Management \\ Studies, School of Management, Pondi- \\ cherry University, Puducherry-605014, \\ India. \\ Email: madansaradha@gmail.com
}

\begin{abstract}
Saving is very important to provide for future contingencies. However, mere saving is also not good. Money saved should be properly invested. Investment should be made such that returns earned outsmart the inflation rate. This descriptive research has made an attempt to study the factors affecting investment decision of Pondicherrians, the proportion of income invested by them and the impact of factors influencing investment decision on this proportion. Results of the study reveal that Pondicherrians have ranked corporate bonds and debentures as their most preferred investment avenue followed by company shares. Pondicherrians largely consider safety of investment followed by returns and risk while making investment decision while they accord moderate consideration to liquidity and capital appreciation. Around one-quarter of the investors are not rational in deciding about their investment. Pondicherrians are investing a little more than one-third of their income (34.61\%). This percentage is expected to increase if safety and returns associated with investment increases. Hence, securities involving less risk and reasonably good returns will be well demanded by Pondicherrians.
\end{abstract}

\section{Keywords}

Investment, Pondicherrians, Proportion of income invested, rational, Absurd, Skeptic

\section{Introduction}

Utility of hard earned money can be well experienced only when it yields fullest joy. Expending all the money earned is not desirable. Saving is very important to provide for future contingencies. However, mere saving is also not good. Money saved should be properly invested. Since the economy is subject to inflation, it is not clever to just save. Instead, investment should be made such that returns earned outsmart the inflation rate resulting in value addition.

\subsection{Investment}

Investment is the process of foregoing current expenditure for future benefits. Income available can be spent either fully or partly. If part of the income is unspent, this amount may be applied on avenues so that it fetches further returns. Hence, investment is the process of utilizing money for earning further money. Investing involves two elements of sacrificing current expenditure and providing for future benefits. Purchasing gold, land, shares, insurance policy or depositing in bank, pension fund or provident fund all constitutes investment as in all cases, current expenditure is sacrificed for the purpose of future gain. Mere savings is risk-free but yields only minimum returns while investments are more risky, yielding higher returns. Investment involves applying money for longer period. Hence, money not needed for the immediate future should alone be invested. 


\subsection{Importance of Investment}

Money is badly needed in all stages of life. Emergencies may arise at any time of life which might demand availability of huge money. To confront such emergency situation, it is important to have money. Money cannot be earned overnight. Earnings will be slow and steady. Hence, it is imperative to set aside a certain proportion of earnings to provide for future contingencies. Some notable reasons for warranting investment are:

1) Transaction Motive: There is always a time lag between money needed for spending and availability of money in the form of income. Paid employees put in a month's hard work and get their salary only at the end of the month or the beginning of the next month. Similarly, entrepreneurs need lot of money to run their business but get receipts from business only after a fair period. Money is needed during the time gap between expenditure and income and investment is needed to bridge this gap. The "Transaction demand for money" prevails in all stages and investment is indispensable to account for this demand.

2) Precautionary motive: Human beings are always precautionary. This is an important feature distinguishing them from animals. They always have to provide for future contingencies such as a sudden hospitalization or loss of job. Money is badly needed to confront these contingencies for which investing is the only option.

3) Speculative Motive: Most people do not lead a contented life. They want to earn more money. They want to use their money to earn more. They want to take advantage of speculative trends in the financial markets and maximize their profits.

4) Education of Children: It is obligatory for everyone to well educate their wards. Education has become very costly. Many opportunities are also available for acquiring quality education but most of these are very costly. It is important to have sufficient money for providing quality education to children for which investment becomes imperative.

5) Self-reliance: Having invested in profitable assets gives a feel of self-reliance and comfort of doing anything independently.

6) Security of Family: Untimely loss of bread-earner should not put the family in a huge financial distress for which well-planned investment is imperative.

Considering the importance of investing, this study has made an attempt to assess the investment pattern of people in Puducherry, factors considered by them to make investment decisions, the proportion of income invested by them and the impact of factors considered important by them for investing on the proportion of income invested.

\section{Review of Literature}

Sultana (2010) attempted to assess the relationship between gender and age of investors and their risk tolerance while Bhardwaj Rajesh et al. (2011) found a significant difference in the nature of savings of government and private school teachers due to significant difference in their pay. The study exposed that private school teachers saved and invested to provide for education and marriage of children while their government counterparts preferred to save to provide for future contingencies.

Mathivannan and Selvakumar (2011) found that teachers lead their livelihood by preparing monthly budgets to exercise effective control over their expenditure while Varsha Virani (2012) found that despite lesser income, teachers were saving in the form of bank deposits to provide for their retirement and for education and marriage of children.

Julie and Agnew (2003) found substantial difference in financial literacy among men and women resulting in women being more risk averse, investing in less risky investments.

Singh Balwinder and Sharma Ruchika (2011) found that working women attach paramount importance to saving and investing to ensure that they possess money required to confront future contingencies.

Study conducted by SEBI-NCAER (2000) revealed that some people with low income and household durables are trading in stock while some others possessing high income are not. The study exposed that individuals account for a mere $7-9 \%$ of the total trading of stock, debentures and mutual funds. Individuals trading in stock do not invest more than Rs. 25,000 for the purpose.

Apil Kapoor (2016) found that investors in both rural and urban areas preferred to invest in real estates as they considered this avenue as less risky and more remunerative. Villagers preferred to invest in farm land while the city people preferred to invest in plots and apartments in urban areas.

Maheswari (2016) found that rural people, irrespective of level of education, preferred investing in government securities, bank deposits and life insurance rather than shares or corporate securities. Low level of income and fi- 
nancial literacy rendered the rural people risk averse, driving them away from investing in corporate securities and other risky investments.

Somasundaram (1998) found that employees of Coimbatore preferred to save in banks and chit funds to provide for future needs which might crop up.

Gaurav Kabra (2010) highlighted that the personal characteristics of investors played a decisive role in their decision about investing.

Karthikeyan (2001) found that older people had greater awareness and inclination towards investing in Post Office savings schemes such as Kisan Vikas Patra, National Savings Scheme and deposit Scheme for Retired Employees.

Andhu and Singh (2004) unearthed that people in Amritsar considered lucidity, security, expediency, economy, market quality and liquidity as the important factors driving their decision to trade in stock. Manish Mittal and Vyas (2008) pointed out that investors are not always rational while deciding about investing. Their investment decision is substantially affected by their emotions and behavioral biases.

Sagar Patil and Virupaxi Bagodi (2021) found that economic conditions, financial statements and technical analysis are the factors largely influencing investment decisions.

Lin, et al. (2019), Mak and Ip (2017) highlighted that investors accord utmost importance to objective and subjective data which influence market returns before arriving at their investment decisions while authors such as Ahmad (2017), Chen and Lo (2019), Yang (2020) have opined that investors are in want of accounting data pertaining to the company before arriving at their investment decisions.

Bae and Dixon (2018) found that investors gather lot of data about investing from web sources and make interpretations of such data before deciding about investing.

Murithi Suriya, et al. (2012) found that investors in India gather information from at least two sources before deciding about their investment. They largely get the thoughts from their family members and friends before going ahead with their investment.

Jaakko and Tikkanen (2011) found that positive perception of an investor about a company induced his urge to invest in its shares. Even financial returns only had a lesser role to play on the investment decision of such investors.

Deshpande and Zimmerman (2010) hinted that financial inclusion and youth empowerment can be accomplished only by developing the thrift of savings among the younger population by providing them with incentives to operate savings account which will exert a positive bearing on their asset ownership.

Gupta and Jain (2008) surveyed 1463 private investors and revealed that shares, mutual fund, exchange-traded gold fund, government securities and bank deposits were their preferred investment avenues. Perception about investing is substantially influenced by their portfolio management, age, income and opinion about quality of market regulation.

A close scrutiny of these studies has revealed that pattern of savings and investment has been extensively researched in the past. This has induced the researchers to try and study the factors considered important by Pondicherrians before deciding about their investment and the influence of these factors on the proportion of income invested by them.

\subsection{Objectives of the Study}

1) To analyze the factors that influence investment decisions of Pondicherrians;

2) To assess the proportion of income invested by Pondicherrians and unearth the impact exerted by factors considered by them before investing, on this proportion.

\subsection{Methodology}

This study is descriptive in nature, based purely on primary data, collected by administering a structured questionnaire to 130 people of Puducherry, selected using Convenience sampling. The questionnaire consists of 2 parts. The first part has statements in Likert's five-point scale to measure the saving and investment pattern of people while the second part consists of questions related to the their profile. The data collected was tested for Reliability and then analysed using SPSS, employing the statistical tools of Mean, Chi-square analysis, Cluster Analysis and Regression.

\section{Data Analysis and Discussion}

\subsection{Profile of the Respondents Studied}

$34.6 \%$ of the respondents are females while $65.4 \%$ are males; $48.5 \%$ are married while $50.8 \%$ are unmarried and 
$0.8 \%$ are separated; $33.8 \%$ of the respondents have monthly family income of less than Rs. 25,000 while $36.9 \%$ have Rs. $25,000-50,000$ and $29.2 \%$ have monthly family income of more than 50,000; $35.4 \%$ are private employees, $13.8 \%$ are government employees, $26.2 \%$ are self-employed and $24.6 \%$ are engaged in other occupations; $8.5 \%$ of the respondents have underwent only schooling while $53.8 \%$ possess degree/ diploma and $37.7 \%$ possess educational qualifications of PG \& more; 50\% of the respondents are aged less than 30 years while 18.5\% are aged 30-45 and $31.5 \%$ are aged more than 45 years; $50.0 \%$ the respondents have a family size of $3,7.7 \%$ of the respondents have a family size of $2,16.2 \%$ have a family size of 3 while $26.2 \%$ have a family size of more than 4 ; $59.2 \%$ of the respondents get investment information from friends and relatives while $46.9 \%$ have got from Internet, $23.8 \%$ from TV, $25.4 \%$ from newspapers while $12.3 \%$ of the respondents seem to get the information from Consultants; $60.8 \%$ manage their investment themselves while 6.2\% manage through brokers and 33.1\% manage through banks; $12.3 \%$ prefer investments involving low risk with low returns while $77.7 \%$ prefer moderate risk with moderate returns and $10 \%$ prefer investments with high risk and high returns.

\subsection{Ranking of Different Avenues of Investment}

The respondents were asked to rank different avenues of investment and the preferred investment avenue was arrived at using Mean Analysis. The results are highlighted in Table 1.

Table 1. Ranking of Different Investment Avenues

\begin{tabular}{cc}
\hline Investment Avenue & Mean \\
\hline Bank Deposit & 37.2077 \\
Mutual funds & 8.3231 \\
Company shares & 6.9923 \\
Corporate bonds and debentures & 1.5692 \\
Insurance premium & 17.8308 \\
Gold and silver & 13.2769 \\
Pension fund & 7.7615 \\
\hline
\end{tabular}

Table 1 suggests that the Puducherry people have ranked corporate bonds and debentures as their preferred investment avenue followed by company shares, real estate, Pension fund, mutual funds, gold \& silver, insurance premium and finally by bank deposits.

\subsection{Factors Considered before Investing}

Investment decision shall be influenced by different factors and an attempt has been made to assess the factors which are seriously considered by the Pondicherrians before investing and the results are depicted in Table 2 .

Table 2. Factors Considered before Investing

\begin{tabular}{ccc}
\hline Factor & Mean \\
\hline Safety & 3.6692 \\
& Liquidity & 3.1846 \\
capital appreciation & 3.2385 & 3.4077 \\
& Returns & 3.3923 \\
\hline
\end{tabular}

Table 2 displays that Pondicherrians largely consider safety of investment followed by returns and risk while making investment decision while they accord moderate consideration to liquidity and capital appreciation. Hence, Pondicherrians accord paramount importance to safety before making investment decisions.

\subsection{Grouping Pondicherrians Using Factors Considered by Them for Investment}

Cluster Analysis has been used to segment the Pondicherrians based on factors considered by them before investing and the outcome is displayed in Table 3. 
Table 3. Grouping Pondicherrians using Factors Considered by them for Investment

\begin{tabular}{ccccccc}
\hline Influencing Factor & C1 & C2 & C3 & F & Sig. \\
\hline Safety & 4.64 & 2.70 & 2.94 & 79.039 & 0.000 \\
Liquidity & 4.05 & 2.00 & 2.69 & 76.736 & 0.000 \\
capital appreciation & 3.93 & 1.48 & 3.23 & 68.827 & 0.000 \\
Returns & 4.51 & 1.78 & 2.83 & 158.486 & 0.000 \\
Risk & 4.44 & 2.04 & 2.75 & 66.659 & 0.000 \\
$\mathrm{~N}$ & 59 & 23 & 48 & &
\end{tabular}

Table 3 showcases the formation of three distinct clusters. The first cluster is labeled as "Rationalist Investors” as these investors have been largely influenced by all the factors suggesting that they consider all the important factors before investing. The second cluster has been named as "Absurd Investors" as these investors have not been influenced by all the factors, suggesting that they do not consider any of the important factors before deciding about investing. The third cluster has been labelled as "Skeptic Investors", as they fall in the neutral category, indicating that they neither consider nor disregard the factors before deciding about investing and hence are skeptical and doubtful. These three clusters consist of 59, 23 and 48 investors respectively. Further, all the factors chosen for this study have significantly contributed to the grouping process as the F values of all factors are statistically significant. The factor of Returns has the highest $\mathrm{F}$ value and hence it makes the highest contribution to the grouping process.

\subsection{Demographic Characteristics of the Clusters Formed on the Basis of Factors Influencing Invest- ment Decision}

The demographic composition of clusters formed on the basis of factors influencing investment decisions of investors has been analysed using Crosstabs and the outcome is portrayed in Table 4.

Table 4. Demographic Characteristics of the Clusters formed on the basis of Factors Influencing Investment Decision

\begin{tabular}{|c|c|c|c|c|}
\hline \multicolumn{2}{|c|}{ Profile } & \multirow{2}{*}{$\frac{\text { Rational investors }}{20}$} & \multirow{2}{*}{$\frac{\text { Absurd Investors }}{13}$} & \multirow{2}{*}{$\frac{\text { Skeptic Investors }}{12}$} \\
\hline & female & & & \\
\hline Gender & male & 39 & 10 & 36 \\
\hline \multirow{3}{*}{ Marital Status } & Married & 35 & 8 & 20 \\
\hline & Unmarried & 24 & 15 & 27 \\
\hline & Separated & 0 & 0 & 1 \\
\hline \multirow{3}{*}{ Monthly Income } & $<25,000$ & 16 & 13 & 15 \\
\hline & $25,000-50,000$ & 22 & 8 & 18 \\
\hline & $>50,000$ & 21 & 2 & 15 \\
\hline \multirow{4}{*}{ Profession } & private employee & 21 & 9 & 16 \\
\hline & government employee & 14 & 2 & 2 \\
\hline & self employed & 13 & 8 & 13 \\
\hline & Others & 11 & 4 & 17 \\
\hline \multirow{3}{*}{ Education } & school level & 4 & 2 & 5 \\
\hline & degree/diploma & 34 & 15 & 21 \\
\hline & PG \&more & 21 & 6 & 22 \\
\hline \multirow{3}{*}{ Age } & $<30$ & 20 & 17 & 28 \\
\hline & $30-45$ & 10 & 3 & 11 \\
\hline & $>45$ & 29 & 3 & 11 \\
\hline \multirow{4}{*}{ Family size } & 2 & 4 & 4 & 2 \\
\hline & 3 & 11 & 3 & 7 \\
\hline & 4 & 33 & 10 & 22 \\
\hline & $>4$ & 11 & 6 & 17 \\
\hline
\end{tabular}


Table 4 showcases that larger number of females and government employees are rational investors followed by almost identical number of absurd and skeptic investors while larger number of graduates/diploma-holders, males, married investors, private employees, those aged in excess of 45 years and those with family size of 3 and 4 are rational investors followed by skeptic investors while there are a few absurd investors. The solitary separated investor is a skeptic investor. Furthermore, larger number of unmarried investors are skeptic investors followed closely by rational investors and finally, by absurd investors while larger number of self-employed are both rational and skeptic followed by absurd investors. Larger number of investors engaged in other professions, those with family size of more than 4 , those possessing school-level and post-graduation \& more as educational qualifications and those aged less than 30 years \& 30-45 years are skeptic investors followed by rational investors and finally, by absurd investors while larger number of investors with family size of 2 are both rational and absurd followed by those who are skeptic.

\subsection{Percentage of Income Invested}

The percentage of income invested by the Pondicherrians has been obtained as an open-ended question and the mean of percentage of income invested is displayed in Table 5.

Table 5. Percentage of Income Invested

\begin{tabular}{cc}
\hline Statement & Mean \\
\hline Percentage of Income Invested & 34.61 \\
\hline
\end{tabular}

Table 5 highlights that the Pondicherrians are investing a little more than one-third of their income (34.61\%).

\subsection{Impact of Factors Considered for Investing on Percentage of Income Invested}

The impact of different factors considered by the Pondicherrians while deciding about their investment on the percentage of income invested has been unearthed using Regression Analysis and the outcome is displayed in Table 6.

Table 6. Impact of Factors Considered for Investing on Percentage of Income Invested

\begin{tabular}{|c|c|c|c|c|}
\hline Variable & B & Std. Error & $\mathrm{F}$ & Sig. \\
\hline Constant & 34.652 & 5.737 & 6.040 & 0.000 \\
\hline Safety & 7.287 & 1.939 & 3.759 & 0.000 \\
\hline Liquidity & 1.731 & 2.052 & 0.844 & 0.400 \\
\hline capital appreciation & -0.494 & 1.686 & -0.293 & 0.770 \\
\hline Returns & 5.529 & 2.090 & 2.645 & 0.009 \\
\hline Risk & 1.177 & 1.478 & 0.0796 & 0.427 \\
\hline R Square & 0.130 & & & \\
\hline
\end{tabular}

Table 6 highlights that the independent variables of safety, returns, risk, capital appreciation and liquidity explain $13 \%$ variance of the dependent variable of percentage of income invested. The table further suggests that safety and Returns exerts significant impact on the percentage of income invested by the Pondicherrians. This implies that if Pondicherrians start according more importance to safety and returns, the percentage of income invested will increase. Based on the results, the following model is derived:

Percentage of Income Invested $=34.652+7.287 *$ Safety $+5.529 *$ Returns

This implies that if the inclination of Pondicherrians towards safety increases by $1 \%$, the percentage of income invested shall increase by $7.287 \%$ while an increase in the inclination of Pondicherrians towards returns by $1 \%$ will increase their percentage of income invested shall increase by $5.529 \%$.

\section{Inferences from the Study}

Puducherry investors have ranked corporate bonds and debentures as their most preferred investment avenue followed by company shares. This is an encouraging scenario as productive investment avenues have been preferred.

Pondicherrians largely consider safety of investment followed by returns and risk while making investment decision while they accord moderate consideration to liquidity and capital appreciation. This implies that Pondicherrians are largely concerned about safety of their investment followed by returns. This is the reason for them preferring 
corporate bonds and debentures as these securities carry guaranteed rate of interest and are also less riskier.

Of the 130 Pondicherrians surveyed, only 23 are Absurd Investors. This implies that around one-quarter of the investors are not rational in deciding about their investment. 59 investors are rational, giving due importance all the important factors before deciding about investing. Similarly, 48 investors also give at least some importance to the factors. Hence, it can be observed that Pondicherrians are reasonably rational in deciding about investments.

Larger number of graduates/diploma-holders, married investors, private and government employees, those aged in excess of 45 years and those with family size of 3 and 4 are rational investors. This suggests that older Pondicherrians with large family and engaged in job are carefully diagnosing all important factors before deciding about investing.

Pondicherrians are investing a little more than one-third of their income (34.61\%). This percentage is expected to increase if safety and returns associated with investment increases. Hence, securities involving less risk and reasonably good returns will be well demanded by Pondicherrians.

\section{Conclusion}

This research has revealed that safer investment offering reasonable returns are well preferred by the Pondicherrians. Further, more than one-third of income is invested by the Pondicherrians which is a good proportion. Most importantly, Pondicherrians have ranked corporate securities as their most preferred avenue of investment. This high propensity of Pondicherrians to invest and that too, in corporate securities, should be utilized by the corporate world so that more funds are available with the corporates to undertake expansion at a fair pace.

\section{References}

A. K. Vashisht, R. K. Gupta. Investment Management and Stock Market, Deep \& Deep Publications Pvt. Ltd, New Delhi, 2005, Page no: 4.

Ahmad, S. (2017). Factors influencing individual investors' behavior: An empirical study of Pakistan financial markets. Journal of Business \& Financial Affairs, 4(6), (2017), pp. 1-8.

Bae, K. H. and Dixon, P. (2018). Do investors use options and futures to trade on different types of information? Evidence from an aggregate stock index. Journal of Futures Markets, 38(2), (2018), pp. 175-198.

Bhardwaj, R., Raheja, R., and Priyanka. (2011). Analysis of Income and Savings Pattern of Government And Private Senior Secondary School Teachers. Asia Pacific Journal of Research in Business Management, Volume 9, Issue 2, Page no.: 44-56.

Chen, H. and Lo, T. (2019). Online search activities and investor attention on financial markets. Asia Pacific Management Review, 24(1), (2019), pp. 21-26.

D. Julie, R. Agnew. (2003). Journal of Social Welfare and Management, Volume 11, Number 2 (Special Issue), April-June, 2019.

Deshpande and Zimmerman. (2010). Savings accounts for young people in developing countries: Trends in practice. Enterprise Development and Microfinance, Volume 21, Issue 4, 10.3362/1755-1986.2010.026.

Gaurav Kabra, Prashant Kumar Mishra, and Manoj Kumar Dash. (2010). Factors Influencing Investment Decision of Generations in India: An Econometric Study. Asian Journal of Management Research, Volume 1, Issue 1, Page no.: 308-326.

Jaakko and Tikkanen. (2011). Individuals’ Affect-Based Motivations to Invest in Stocks: Beyond Expected Financial Returns and Risks. Journal of Behavioral Finance, Volume 12, Issue 2.

Kapil Kapoor. (2016). An Empirical Research on the Investment Behavior of Rural and Urban Investors Towards Various Investment Avenues: A Case Study of Moradabad Region. TMIMT International Journal "Special Issue- 2016", ISSN 2348-988X.

Karthikeyan, B. (2001). 'Small Investors’ Perception on Post Office Small Savings Schemes. Unpublished thesis, Madras University, Tamilnadu, India.

L. Bajtelsmit and A. Bernasek. (1996). "Why do women invest differently than men?” Financial Counseling and Planning, Volume 7, 1996, pp. 1-10.

Lin, J., Hou, T. C., and Hsiao, Y. (2019). Introduction to the special issue of "Big data analytics": Using financial and non-financial information. Asia Pacific Management Review, 24(10), (2019), pp. 1-10.

Mak, M. K. Y. and Ip, W. H. (2017). An exploratory study of investment behaviour of investors. International Journal of 
Engineering Business Management, 9(2017), pp. 1-12.

Mathivannan, S. and Selvakumar, M. (2011). Saving and Investment Pattern of School Teaches-A study with reference to Sivakasi Taluk, Tamil Nadu. Indian Journal of Finance.

Mittal, Manish, and Vyas, R. K. (2008). Personality Type and Investment Choice: An Empirical Study. Journal of Behavioral Finance, Volume 5, Issue 30, pp. 6-16.

Murithi Suriya, Narayanan, and Arivazhagan. (2012). Investors Behaviour in Various Investment Avenues-A Study. International Journal of Marketing and Technology, July 2012, Volume 2, Issue 7, ISSN: 2249-1058.

National council of applied Economics research (NCAER). (2002). "Household savings and investment behavior in India”.

Sagar Patil and Virupaxi Bagodi. (2021). A study of factors affecting investment decisions in India: The KANO way. Asia Pacific Management Review, Volume 26, Issue 2, p. 10.

Sandhu and Singh. (2004). International Journal for Research in Engineering Application \& Management (IJREAM), Volume 4, Issue 3, June 2018, ISSN: 2454-9150.

SEBI-NCAER. (2000). Journal of Social Welfare and Management, Volume 11, Number 2 (Special Issue), April-June 2019.

Singh Balwinder, Ms. Sharma Ruchika. (2011). Asia Pacific Journal of Research in Business Management, Volume 2, Issue 3, ISSN 2229-4104.

Somasundaram, V. K. (1998). A study on the savings and investment pattern of salaried class in Coimbatore district. IUP Journal of Behavioral Finance, Volume 6, Issue 2, p. 28.

Sultana, S. T. (2010). An empirical study of Indian individual investor's behavior. Global Journal of Finance and Management, Volume 2, Issue 1, pp. 19-33.

Virani, V. (2012). Saving and Investment pattern of school teachers-A study With special reference to Rajkot City, Gujrat, Abhinav National Refereed journal of research in Commerce and Management, Volume 2, Issue 4, pp. 2277-1166.

Yang, A. S. (2020). Investors' trust and financial participation: Latent difficulty measurement. Asia Pacific Management Review, 25(2), (2020), pp. 87-98. 